ESTUDIOS

J. Silvio Botero G., CSsR.

Academia Alfonsiana-Universidad de Letrán

ROMA

\title{
El cónyuge injustamente abandonado. Una situación que reclama justicia
}

\section{INTRODUCCIÓN}

Un síntoma social altamente preocupante es el fenómeno del 'fracaso conyugal'. Muchas causas contribuyen a hacerlo más frecuente: entre otras, la permisividad, el relativismo ético, la descristianización, son factores que influyen y que están creando una mentalidad "de confusión y de error acerca de la doctrina de la Iglesia sobre la indisolubilidad del matrimonio", como afirma Juan Pablo II en la Exhortación Apostólica Familiaris consortio (n. 84). Contribuye igualmente a este problema la inmadurez afectiva cuyos estragos se difunden cada día más.

Sin duda que un problema que agrava la situación de las parejas fracasadas en el momento presente es el caso del cónyuge que se ve abandonado por parte del consorte injusta e inocentemente. Incluso, a veces se alega, como motivo para este tipo de abandono, la necesidad de una realización personal.

El problema del cónyuge inocentemente abandonado urge un análisis serio desde diversas perspectivas: sea desde una teología renovada del matrimonio, sea desde una visión del nuevo derecho canónico que piense de verdad en la salus animarum (c. 1752), sea desde una actitud pastoral que acoja la orientación de flexibilidad que se está insinuando fuertemente dentro de la Iglesia.

El propósito de estas páginas es el de ofrecer una reflexión que ayude al pastoralista a hacer frente a esta situación frecuente, dolorosa y que al presente no tiene otra solución que la del heroísmo cristiano.

\section{UNA BREVE VISIÓN HISTÓRICA}

De entrada se debe poner de presente que son pocos los estudios, al menos aquellos que conozco, sobre el tema (1). Una explicación de la escasez de literatura

(1) Cfr. Carlo DE SANCTIS, "Il pensiero della Chiesa sul problema del coniuge abbandonato senza colpa", Apollinaris 48 (1975) 201-221 e 402-440; GRUPPO DI RICERCA DI TORINO, a cura di, "È possibile un secondo matrimonio cristiano per il coniuge innocente abbandonato?", en Sul Divorzio, a cura di F. Vittorino Joannes, Mondadori, Verona 1970, 187-214; J. Silvio Botero G., 
al respecto es, sin duda, el respeto a una tradición que pesa fuertemente: comenzando el segundo milenio la unidad doctrinal y disciplinaria de la Iglesia reforzó el principio de la indisolubilidad del matrimonio, hasta el punto de que el Concilio de Trento formulara un anathema sit contra quien se permita afirmar que "la Iglesia erra cuando enseña que el vínculo del matrimonio no puede ser disuelto por el adulterio de uno de los cónyuges, y que ninguno de los dos, ni siquiera el cónyuge inocente que no ha dado motivo al adulterio, puede contraer un nuevo matrimonio mientras viva el cónyuge..." (Denz. 1807).

La tradición doctrinal y disciplinar de la Iglesia Católica es ciertamente más severa a este respecto que la de la Iglesia Ortodoxa y que la de las Comunidades Protestantes. Estas últimas han mantenido una actitud de mayor flexibilidad frente a los conflictos conyugales (2). Sin embargo, la Iglesia Católica en el Sínodo de Obispos sobre la familia (1980) al formular las "43 Proposiciones" para la elaboración posterior de la Exhortación Apostólica (Familiaris consortio), sugirió "la posibilidad de promover la solicitud pastoral en favor de los divorciados llevando a cabo una investigación más profunda y teniendo en cuenta la praxis de la Iglesia Oriental a fin de hacer más efectiva la misericordia pastoral" (3).

Con ocasión del Concilio Vaticano II, Mons. Elías Zoghbi, Vicario Patriarcal para los Melquitas en Egipto, tuvo una intervención audaz (29 de Sept. 1965): más grave que el problema del control de los nacimientos, decía en el aula conciliar, es la del cónyuge inocente que en la flor de la juventud llega a encontrarse solo por culpa del otro consorte. Permanecer solo y conservar la castidad por el resto de la vida es una solución que supone una virtud heroica y una fe poco común. Estas personas frecuentemente acaban contrayendo otra unión ilegítima fuera de la Iglesia, y se angustian en su conciencia pensando que deberán ser sujetos fuera de serie o arriesgarse a la condenación. Arguiía en su favor que el heroísmo, el estado de perfección, jamás han sido impuestos dentro de la Iglesia bajo pena de condenación. Por tanto, la Iglesia debería tener medios suficientes para proteger al cónyuge inocente contra las consecuencias del pecado del otro cónyuge. No parece oportuno que la continencia perpetua, que es un estado de perfección, pueda ser impuesta como una obligación, como si fuera un castigo a quien ha sido traicionado (4).

La intervención de Mons. Zoghbi produjo, como es lógico, la reacción de algunos padres conciliares, entre ellos la del cardenal Ch. Journet, que recordó la línea tradicional de la Iglesia malinterpretando en algún momento las relaciones IglesiaEstado en Oriente. La prensa escrita italiana se hizo eco de la buena acogida que tuvo el planteamiento del Vicario Patriarcal y comentaba: "un bel dì verrà, ma non è ancora per domani”, queriendo decir que es una buena perspectiva para un futuro no lejano.

"El cónyuge abandonado inocentemente: un problema a replantear", Estudios Eclesiásticos 73 (1998) 443-472.

(2) Cfr. J. Silvio Botero G., "El conflicto 'persona' - 'ley': un tema para el diálogo ecuménico", Scriptorium Victoriense 45 (1998) 107-133.

(3) Sinodo dei Vescovi sulla Famiglia, "Le 43 proposizioni”, Il Regno-Doc. 26 (1981) 386-397. La traducción es mía.

(4) Cfr. Giovanni CAPrile, a cura di, Il Concilio Vaticano II. Cronache del Concilio Vaticano II edite da 'La Civiltà Cattolica', Quarto periodo 1965, vol. V, La Civiltà Cattolica, Roma 1968, 130-131. 
El segundo milenio, fiel a la estricta observancia de la doctrina y de la disciplina eclesial sobre la indisolubilidad del matrimonio, no dará pie para que se ventile el problema del cónyuge inocentemente abandonado. El problema está presente ciertamente; un ejemplo son los casos en que los príncipes abandonan a sus consortes para establecer una nueva unión: Lotario, Enrique IV, Enrique VIII de Inglaterra, Felipe I y Felipe II de Francia, Napoleón, etc (5). La Iglesia, a través de la autoridad pontificia, mantuvo incólume el principio de la indisolubilidad del matrimonio (6), no obstante los esfuerzos de la autoridad civil por abrir espacio al matrimonio civil y al divorcio.

Un período significativo en la historia de la Iglesia es la época de los Penitenciales (7); entre estos merece citarse el Penitencial de Burcardo de Worms (10081012) que, a propósito del tema del cónyuge inocente, expone el siguiente caso: "tu mujer cometió adulterio estando tú informado de ello, o quizás instigada por ti? En caso afirmativo, harás penitencia a pan y agua durante 40 días a lo largo de siete años consecutivos, y uno de ellos a pan y agua. Tu mujer, si puede probar que actuó contra su voluntad, a causa de tu instigación, si no puede vivir en continencia, puede desposar a quienquiera pero siempre en el Señor. Tú, en cambio, permanecerás por siempre sin volver a casarte" (8).

Giorgio Picasso comenta así la actitud del Penitencial de B. de Worms en relación al cónyuge inocente: no obstante las incertidumbres del Alto Medievo acerca del vínculo conyugal, es evidente que no puede ponerse al mismo nivel casos como el del adulterio, el del cónyuge inocente y el del consorte culpable. La autorización de casarse de nuevo con la condición "pero delante del Señor", quiere decir que se debe pesar bien en la conciencia la decisión que se quiere tomar (9).

El llamado Penitencial del seudo Teodoro (s. IX) recoge en los cánones 5, 31, 61,140 , diversos casos en los que se autoriza a uno de los esposos (normalmente a él) casarse de nuevo: "a quien le ha sido quitada la esposa a la fuerza por el enemigo y no la puede recuperar, le es lícito tomar otra. En el caso en que ella regresara, no está obligado su marido a retomarla porque ya tiene una. Ella podrá tomar otro marido si ya había tenido uno solo" (10). Antonio García y García afirma que la mayor parte de los penitenciales admiten el divorcio vincular y el paso a un segundo matrimonio viviendo aún el primer consorte, por una serie de causas..." (11).

En la segunda mitad del primer milenio los concilios regionales dan noticia de diversas causas que podrían parangonarse con la situación del cónyuge inocentemente abandonado:

(5) Cfr. Victor J. Pospishil, Divorzio e nuovo matrimonio, Bompiani, Milano 1968, 217-219.

(6) Cfr. Pierre Adnés, El Matrimonio, Herder, Barcelona 1969, 122, 193.

(7) Los Penitenciales corresponden a una época determinada de la historia: entre la segunda parte del primer milenio y comienzos del segundo. Para facilitar a los confesores el ejercicio del ministerio penitencial algunos autores ofrecían por escrito elencos de los pecados con la penitencia a imponer al penitente.

(8) Cyrille Vogel, Il peccatore e la penitenza nel Medioevo, LDC, Leumann (Torino) 1988, 155. La traducción es mía.

(9) Cfr. Giorgio PICASso, a cura di, A pane e aqua. Peccati e penitenze nel Medioevo. Il Penitenziale di Burcardo di Worms, Europia, Novara 1986, 44.

(10) Cfr. Victor J. PosPishiL, Divorzio e nuovo matrimonio...., 213.

(11) Antonio GARCíA Y GARCíA, "La indisolubilidad matrimonial en el primer milenio, con especial referencia a los textos divorcistas”, en El vínculo matrimonial. ¿Divorcio o indisolubilidad?, colaboran T. García Barberena y otros, BAC, Madrid 1978, 148. 
- el Concilio de Verberie (752? - 753?) señala posibles casos: "si una mujer atenta con la complicidad de otras personas dar muerte a su marido, y este mata a alguno de los conspiradores, si él lo puede probar, tal marido puede repudiar a su mujer, y si lo desea puede tomar otra" (Canon 5) (12).

El canon 9 plantea otro caso: "si un hombre, impulsado por una necesidad inevitable, escapa a otro ducado o provincia, o si acompañó a su señor, al que había prometido fidelidad, no pudiendo negarse, y su esposa, pudiendo y siendo capaz, rehúsa acompañarle a causa del apego a su familia, y a sus cosas, ella permanecerá sin casarse durante todo el tiempo que viva su marido al que no quiso seguir. Pero su marido, que vive en otro país obligado por la necesidad acuciante, si no tiene esperanzas de volver ya nunca más a su país y no puede vivir en continencia, puede tomar otra mujer, tras haber hecho penitencia".

- $\quad$ El Concilio de Compiegne (757) contempló una problemática muy similar a la de Verberie: "si un leproso permite a su mujer que está sana casarse con otro hombre, ella puede hacerlo. Dígase lo mismo cuando la leprosa es la mujer" (Canon 19) (13).

- El Concilio de Arlés (314) quizás sea el primer testimonio de un concilio que admite un nuevo matrimonio al cónyuge inocente. El tenor del canon es discutible: los investigadores analizan si hubo o no una interpolación. El canon afirma que los maridos que hayan cogido en adulterio a su mujer, y si ellos son jóvenes aún, se les prohíbe casarse ("no se les prohíbe"); se les aconseja que mientras vivan las esposas aunque sean adúlteras, no se casen de nuevo. La polémica se trenza entre quienes leen prohibentur nubere y quienes quieren leer non prohibentur nubere (14).

Este problema de posibles interpolaciones en los documentos que aluden a la polémica sobre un posible divorcio en determinados situaciones, parece que sí se dio; es el caso del Concilio de Arlés, según algunos autores. García y García afirma que "en el paso de Regino de Prüm a Burcardo un texto divorcista se hace de signo contrario mediante la adición de una partícula negativa" (15).

Entre los pontífices de aquel milenio es posible encontrar soluciones semejantes. Gregorio II (715-731) respondía a una pregunta del Obispo de Maguncia, S. Bonifacio, de este modo: "me preguntas si una mujer, afectada de enfermedad no puede corresponder al débito a su marido, ¿qué ha de hacer su cónyuge? Lo mejor sería que él permaneciera así observando la continencia, pero dado que es algo que exige una elevada virtud, el que no puede observar la continencia, mejor es que se case; sin embargo, que no prive de su ayuda a quien la sola enfermedad la impide y no es excluida de su derecho por una falta detestable" (16).

(12) Francisco LozAno, Divorcio y nuevo matrimonio, Verbo Divino, Estella (Navarra) 1971, 142.

(13) Francisco LoZANo, Divorcio y nuevo matrimonio ..., 148.

(14) Cfr. Charles J. Hefele, Historie des Conciles d'après les documents originaux, I/1, Letouzey et Ané, Paris 1907, 287-288.

(15) Antonio GARCíA Y GARCÍA, "La indisolubilidad matrimonial en el primer milenio...", 155.

(16) Francisco LoZANo, Divorcio y nuevo matrimonio ..., 149-150. 
A este respecto es interesante el comentario que hace el Decreto de Graciano: la decisión del Papa está en clara contradicción con la enseñanza de los cánones y del Evangelio, pero la disposición pontificia aparece en consonancia con la práctica de la Iglesia de aquella época (17).

Siguiendo hacia atrás en la historia llegamos hasta los Padres de la Iglesia primitiva. Entre ellos merece mención especial S. Epifanio de Salamina († 403); a él se le atribuye esta sentencia: "quien no puede contenerse después de la muerte de la primera mujer, o quien está separado de ella por un motivo válido como la fornicación, el adulterio u otro pecado, si se casa la palabra divina no lo condena ni lo excluye de la comunidad o de la vida; lo tolera a causa de su debilidad. No se le admite tener dos esposas; pero si efectivamente se ha separado de la primera mujer, puede tomar otra según la ley si tal es su deseo" (18). Una razón que S. Epifanio añade a su argumentación en favor de la benignidad es la de, no obstante la nueva unión, llevar por otra parte una vida honesta y piadosa (19).

S. Cirilo de Alejandría (375?-444) empleaba una imagen sugestiva para invitar a distinguir entre lo que es esencial y lo que es accidental: los navegantes, encontrándose en peligro de naufragar a causa de alguna tempestad, suelen echar al agua parte de la mercancía para salvar el resto; así nosotros, decía, cuando no es posible salvaguardar lo que es fundamental, dejamos de lado algunas cosas para no llevar a la ruina la totalidad (20). Con esta imagen ya estaba anunciando la categoría de la 'Economía' (21), célebre en Oriente.

El Ambrosiaster, documento escrito hacia el 380 y atribuido por mucho tiempo a S. Ambrosio, afirmaba: es lícito a un hombre volver a casarse en el caso en que haya despedido a su mujer pecadora, porque el varón no está limitado en sus derechos como sí lo está la mujer (22).

Orígenes (183-254) se hacía la misma reflexión ya vista anteriormente; decía que la conducta de algunos obispos de su tiempo respecto a la indisolubilidad del matrimonio era ciertamente contraria a la Sagrada Escritura; pero consideraba que el volver a casarse era un 'mal menor'. Ya entonces estaba en uso una doble fórmula para emitir un juicio contra algún vicio: $\kappa \alpha \tau \alpha \varepsilon \pi \imath \tau \alpha \gamma \varepsilon \nu$ (según el rigor de la ley) y $\kappa \alpha \tau \alpha \sigma v \gamma \gamma о \mu \varepsilon v$ (según indulgencia) (23): el principio evangélico de la indisolubili-

(17) Cfr. Victor J. Pospishil, Divorzio e nuovo matrimonio, Bompiani, Milano 1968, 189; Nicolas IUNG, Evolution de l'indissolubilité. Remariage religieux des divorcés, P. Lethielleux, París 1975, 81-82.

(18) S. Epifanio de SAlamina, Panarion o Adversus Haereses 59, 4-6, PG 41, 1024-1028.; Calogero Riggi, "S. Epifanio divorzista?", Salesianum 33 (1.971) 605; Victor J. PosPISHIL, Divorzio e nuovo matrimonio..., 166.

(19) S. Epifanio DE SALAminA, "Praesertim si caeteris in rebus religiosus ille sit, et ad divinae legis praescriptum vitae suae rationes accommodet", Panarion o Adversus Haereses 59, 4-6, PG 41, 1026.

(20) Cfr. S. Cirilo DE AlEJANDRÍA, "Epist. 56 ad Gennadium presbiterum”, $P G$ 77, 320.

(21) La 'Economía', como la piensa la Iglesia Oriental, equivale, según Kotsonis, a una derogación del rigor de la ley bajo ciertas condiciones, sea por necesidad o buscando el mayor bien de alguno o de toda la Iglesia. Cfr. Basilio PETRÀ, Tra cielo e terra. Introduzione alla teologia morale ortodossa contemporanea, EDB, Bologna 1992, 106.

(22) Cfr. Victor J. PosPishil, Divorzio e nuovo matrimonio...., 165.

(23) Cfr. Charles MunIER, "Le temoignage d'Origène en matière de remariage après séparation", $R D C$ 28 (1978) 17, 20, 27. 
dad debería quedar siempre a salvo según el rigor de la ley, pero en los casos concretos se debía ser benigno siguiendo el principio de la flexibilidad.

Si se sigue con atención la línea trazada por los Padres de la Iglesia y por los concilios en lo que respecta al modo como afrontan la ruptura del matrimonio, se llega a unas conclusiones sencillas: en primer lugar, la posibilidad de 'segundas nupcias' en un comienzo, aun en el caso de los viudos, no era admisible; solo gradualmente se irá introduciendo; en segundo lugar aparece la distinción entre el trato dado a los clérigos que han roto su propio matrimonio y el trato a dar a los laicos divorciados; en tercer lugar, los motivos para aceptar una conducta de benignidad van en aumento: en un principio, se autorizaba un nuevo matrimonio en razón del adulterio y del ingreso en la vida monástica; posteriormente se acogerán otras causas como se ha podido observar (24); otras razones que no mencionan los tratadistas pero que aparecen en los documentos son la edad joven y el peligro de incontinencia. Otro dato significativo que emerge de la panorámica del primer milenio es el trato igual que se da progresivamente a varones y mujeres. Será con el comienzo del segundo milenio cuando la disciplina se hace más rigurosa.

Estos pocos testimonios enunciados son una prueba de la actitud de flexibilidad que observó la Iglesia primitiva frente a los conflictos conyugales. Iung ofrece una lista de 15 documentos a favor de la indisolubilidad y de 8 documentos en pro de la tolerancia. Entre los motivos para la tolerancia de la disolución del vínculo y la posible autorización de un nuevo matrimonio aparecen estos: el adulterio, el ingreso en la vida monástica, la salud, una separación duradera, el atentado contra el cónyuge, etc. Son causas que consideradas desde la 'analogía' (25) podrían dar fundamento a una apertura teológico-canónica frente a la situación de los cónyuges abandonados injustamente.

La 'analogía' en este caso se puede establecer entre diversos aspectos semejantes-desemejantes dentro de la teología del matrimonio: la benignidad de la Iglesia Ortodoxa hoy quiere ser tímidamente imitada por la Iglesia Católica; como el sacramento de la Penitencia ha tenido una notable evolución para da cabida a la debilidad humana, del mismo modo la teología y el derecho eclesiásticos deberán evolucionar para acoger la benignidad pastoral; en la doctrina social de la Iglesia se reconoce un amplio margen de acción a los laicos; del mismo modo, la doctrina moral acerca del matrimonio debería escuchar la experiencia de los casados; como la Iglesia antigua que fue ampliando el número de causas de tolerancia frente a la ruptura del matrimonio, en alguna forma la Iglesia de hoy va aceptando progresivamente nuevas causales de disolución del vínculo; el catecumenado penitencial, que hacían los paganos convertidos para acceder al bautismo, puede ser una perspectiva de otro 'catecumenado' para los divorciados que desean 'regularizar' su situación. La Iglesia de hoy puede hallar en la Iglesia primitiva elementos de inspiración y de ejemplo para propiciar una nueva actitud.

(24) Cfr. Antonio García y GarcíA, "La indisolubilidad matrimonial en el primer milenio...”, 148-151.

(25) La 'analogía' es una especie de comparación que tiene cabida tanto en la teología como en el derecho canónico. Del Cura la define como "la comparación o proporción entre dos cosas esencialmente distintas en virtud de alguna relación de semejanza relativa entre ellas". Cfr. A. DEL CURA, "Sobre la analogía. Síntesis del pensamiento de S. Ramírez", Estudios Filosóficos 22 (1973) 91. 


\section{LA TEOLOGÍA POSTCONCILIAR OFRECE NUEVAS POSIBILIDADES}

El Concilio Vaticano II puso a la raíz de su reflexión unos puntos básicos. En primer lugar, la centralidad que da al 'hombre': “es la persona del hombre la que hay que salvar" (GS. n. 3). Se propuso en segundo lugar y en forma decidida abrir espacio al 'amor humano'. Y un tercer elemento es la acogida desprevenida que hace de la sexualidad. Estos tres puntos (no se pretende ser exhaustivo) constituyen una amplia base para afirmar que de verdad el Concilio estaba seriamente interesado en operar una fuerte 'renovación' (26) dentro de la Iglesia.

Tratándose de perfilar una reflexión teológica sobre la condición del 'cónyuge inocentemente abandonado', estos tres elementos subrayados dan la posibilidad de repensar la actitud doctrinal, disciplinar y pastoral de la Iglesia frente a los divorciados vueltos a casar (27), y en especial, en relación con el caso del cónyuge injustamente abandonado.

El énfasis que el Concilio ha dado al 'hombre' haciéndolo 'centro' de su enseñanza es clave en esta tarea de 'humanizar' la teología y el derecho tradicionales. Con este acento el Concilio señala un horizonte nuevo a la historia precedente, fuertemente marcada por el legalismo, la severidad y la importancia dada a las cosas. Un horizonte en el que es el hombre como 'ser histórico' el que dirige el rumbo de la historia. Se ha hecho prevalecer el opus operis (la acción en sí) y no tanto el opus operantis (la persona humana). De ahí la cabida que se da hoy a la conciencia responsable.

La postmodernidad está creando lo que G. Morra llama il quarto uomo (el cuarto tipo de hombre) (28). Este 'cuarto modelo de hombre' es el que otros designan con el nombre de 'hombre light (débil, superficial)' (29). Entre otras características que tipifican al hombre light se enumeran estas: desgano frente a la ley y entusiasmo especial por el afecto, el sentimiento; es un hombre centrado solo en el 'presente' dejando de lado el pasado que no le interesa y el futuro del que no se cuida para nada; la búsqueda del placer a toda costa es el afán preponderante, descuidando el esfuerzo y la abnegación; en cuestión de ética, prevalece en él el relativismo, como consecuencia de su individualismo y de su subjetivismo (30).

Si relacionamos el tipo de hombre que exige el principio evangélico de la indisolubilidad del matrimonio con la imagen que la postmodernidad nos da del hombre de hoy, se diría que el hombre postmoderno difícilmente capta y menos aún es capaz de comprometer toda su persona en una alianza de amor con el otro hasta la

(26) El concepto de 'renovación', según M. D. Chenu, aparece por lo menos 31 veces en los documentos del Concilio.

(27) Cfr. J. Silvio Botero G., "Divorciados vueltos a casar. Principios de base para una nueva actitud", Laurentianum 41/3 (2000) 353-378.

(28) Cfr. Gianfranco Morra, Il quarto uomo. Postmodernità o crisi della modernità?, Armando, Roma 1992.

(29) Cfr. Enrique Rojas, El hombre 'light'. Una vida sin valores, Temas de hoy, Madrid 1995.

(30) Cfr. Enrique Gervilla, Postmodernidad y educación. Valores y cultura de los jóvenes, Dykinson, Madrid 1993, 66; Eugenio Alburquerque, "Lectura de la realidad ética de los jóvenes desde la postmodernidad", en Moral cristianan y pastoral juvenil. Fundamentos para una propuesta ética, CCS, Madrid 1990, 17-30. 
muerte. Sin una buena dosis de fe cristiana es casi imposible. Pero sucede que también el plano de la fe está tremendamente debilitado en el hombre postmoderno.

La fidelidad conyugal no se conjuga con la mentalidad postmoderna. B. Borsato ha descrito en tres líneas lo que ha significado la fidelidad en la historia: en épocas pasadas, ser fiel era mantener la palabra dada; en la postmodernidad la fidelidad solo se concibe como fidelidad a mi proyecto personal; en un futuro deberá expresar la fidelidad al otro (31). La postmodernidad, por tanto, no favorece en ningún modo un proyecto de fidelidad al otro y para siempre.

El amor humano es una de las grandes conquistas logradas por el concilio. Hubo un largo período en que el amor humano fue un desconocido en la teología; se concebía el amor como una debilidad, como una necesidad, y por esta razón se le atribuía a los seres débiles; los dioses griegos no amaban a los hombres. Cuando el cristianismo habló de un Dios que ama a la humanidad, esto constituyó motivo de escándalo.

El Concilio prácticamente acabó con la división entre $\alpha \gamma \alpha \pi \eta$ (amor espiritual) y $\varepsilon \rho \omega \varsigma$ (amor sensible, material) cuando se trata del afecto recíproco entre varón y mujer: "este amor por ser eminentemente humano, ya que va de persona a persona con el afecto de la voluntad, abarca el bien de toda la persona, y, por tanto, es capaz de enriquecer con una dignidad especial las expresiones del cuerpo y del espíritu..." (GS. n. 49).

Juan Pablo II en su primera carta encíclica Redemptor hominis (4 marzo 1979) siguiendo la línea del Concilio concibe al ser humano desde el amor. El hombre ya no se define según el cogito, ergo sum, sino desde el amo, ergo sum. Por esta razón el Papa afirma que el hombre no puede vivir sin amar; encuentra sin sentido la existencia si no le es revelado el amor, si no se encuentra con él, si no se lo apropia y lo experimenta (Cfr. n. 10).

El amor humano es una realidad inmensamente rica; la III Conferencia General del Episcopado Latinoamericano en su documento de Puebla alude a 'los cuatros rostros del amor humano' (n. 583). En este momento interesa hacer referencia al 'amor esponsal' que tiene como característica particular la 'reciprocidad', a diferencia de los otros (amor paterno-materno, amor filial y fraterno) que no exigen necesariamente tal condición. Precisamente, es la reciprocidad la que funda el sacramento del matrimonio, de tal manera que no existiendo dicha reciprocidad no se puede hablar de su dimensión sacramental.

Amarse recíprocamente, en esto consiste la vocación del matrimonio. Juan Pablo II ha afirmado que "el amor es la vocación fundamental e innata de todo ser humano" (FC. 11). El Papa concibe el amor humano como una 'donación', y “el único lugar que hace posible esta donación total es el matrimonio, es decir, el pacto de amor conyugal o elección consciente y libre con la que el hombre y la mujer aceptan la comunidad íntima de vida y amor, querida por Dios..." (FC. n. 11). Siendo el matrimonio una vocación, se sigue que esta exige su realización en forma humana.

De estas pocas premisas se deduce que el amor conyugal constituye ciertamente lo que los teólogos llaman el 'sacramento del amor', de donde se derivan consecuencias de trascendencia.

(31) Cfr. Battista Borsato, Vita di coppia. Linee di spiritualità coniugale e familiare, EDB, Bologna 1993, 90-94. 
La reivindicación positiva de la sexualidad humana es el tercer elemento que se enunció atrás como uno de los logros mejores del Concilio. Es un elemento que está en estrecha relación con el ser del hombre y con el amor humano. El Vaticano II, para poner de relieve la sexualidad del hombre y su relación con el amor, va directamente a destacar el sentido de la cópula conyugal: "este amor se expresa y perfecciona singularmente con la acción propia del matrimonio. Por ello los actos con que los esposos se unen íntima y castamente entre sí son honestos y dignos, y, ejecutados de manera verdaderamente humana, significan y favorecen el don recíproco..." (GS. n. 49).

La tradición eclesial, tratando de superar el tabú sexual, ha intuido una relación especial entre la alianza de Yahvé con su pueblo en el A.T. y la alianza de Cristo con la Iglesia en el N.T. Esta alianza tenía el momento cumbre de su realización en el banquete de comunión. Esto ha dado pie para que se establezca una relación entre el sacramento del matrimonio y el sacramento de la eucaristía (32). De ahí que se relacionen dos expresiones que afectan a uno y otro sacramento: la 'alianza de comunión' y el 'banquete de la alianza'.

Hay un detalle que hace pensar: S. Roberto Belarmino, Pío XI en su encíclica Casti connubii y Juan Pablo II en Familiaris consortio (n. 57) han hecho alusión a la relación existente entre matrimonio y eucaristía: el matrimonio es semejante a la eucaristía en su nacimiento y origen (dum fit) y en su permanencia (dum permanet). "Porque este sacramento (del matrimonio) es como la eucaristía, que no solamente es sacramento mientras se confecciona, sino todo el tiempo que permanece" $(C C . \mathrm{n}$. 116). El detalle que se quiere destacar consiste en que hasta hoy, al parecer, no se han deducido las consecuencias que se derivan de esta comparación.

Otro detalle más que no ha tenido el relieve que se merece es la mención al 'perfeccionamiento' del matrimonio mediante la relación sexual de los esposos, a que hace referencia el Concilio en varias ocasiones. El empleo del término 'perfeccionamiento' es otro intento de 'renovación' del Concilio en materia matrimonial. La doctrina tradicional había acentuado el elemento de la 'consumación del matrimonio’ (c. 1015 § 1-2) del viejo Código de Derecho Canónico, con características, a juicio de los comentadores, un tanto biologicistas.

Usar el vocablo 'perfeccionamiento' orienta en una dirección distinta: no será tanto la primera cópula conyugal la que define el matrimonio ('matrimonio rato y consumado'), cuanto la misma vida marital; el Concilio alude no al primer acto, sino a "los actos con que los esposos se unen íntima y castamente entre sí...". Jean Bernhard y otros juristas han introducido en la reflexión canónica el concepto de 'consumación existencial' (33). La visión de la sacramentalidad como un proceso en búsqueda de la plenitud (la vida conyugal debe hacerse cada vez más expresiva) es un concepto que aflora en la teología renovada del matrimonio. Los teólogos aluden a una sacramentalidad natural o embrionaria, cristiana y eclesial, no como situaciones estáticas, sino como el revelarse de un camino progresivo y unitario.

(32) Cfr. Francesco MARINELli, "Matrimonio ed Eucaristía”, Lateranum 56 (1990) 117-142; J. Silvio Botero G., "Eucaristía y matrimonio. Fundamento de una relación”, Studia Moralia 35 (1997) $375-400$

(33) Cfr. Jean Bernhard, "A propos de l'hypothèse concernant la notion de 'consomation existentielle' du mariage”, RDC 20 (1970) 184-192. 


\section{UNAS CONSECUENCIAS - RETO PARA LA IGLESIA}

Después de exponer una secuencia histórica del problema y de plantear lo que podría llamarse 'principios de base', llega el momento de concluir. Se trata de deducir unas pocas consecuencias siguiendo cada uno de los tres elementos propuestos a partir de la perspectiva renovadora del Vaticano II.

Una primera consecuencia toca el tema del hombre de hoy. A la debilidad y superficialidad que caracterizan al hombre postmoderno se debe añadir la condición histórica de desarrollo continuo y progresivo normalmente. Juan Pablo II escribe en Familiaris consortio que "el hombre (...) es un ser histórico que se construye día a día con sus opciones numerosas y libres; por eso él conoce, ama y realiza el bien moral según diversas etapas de crecimiento" (n. 34).

La condición de hombre pecador, a la que se deben sumar las características del hombre postmoderno, y aún más, la inmadurez que se observa en el joven de la época presente, debe urgir una mayor cautela en la preparación a la celebración del matrimonio y una mayor benignidad frente a las parejas que han fracasado en su intento de construir una comunidad de amor y de vida.

¿Cómo conjugar en la perspectiva jurídico-canónica actual la edad hábil para contraer matrimonio y la 'discreción de juicio' (c. 1095 § 2) necesaria para asumir los derechos y deberes esenciales del matrimonio? Es un conflicto que no se afronta debidamente: el derecho natural al estado del matrimonio como vocación del varón y de la mujer y el sentido de responsabilidad que exige una opción tan seria como es el matrimonio. Siempre se ha afirmado que el matrimonio es un compromiso mucho más grave y serio que otros.

Muchas veces se acepta a la celebración del matrimonio a personas que no garantizan el grado necesario de madurez y de responsabilidad so pretexto de evitar una unión consensual o matrimonio de hecho. ¿No sería preferible tolerar una unión consensual, que con un acompañamiento pastoral pueda alcanzar la madurez necesaria para un compromiso válido?

Tratándose de un fracaso conyugal, el cónyuge inocentemente abandonado, que no puede garantizar la observancia de la continencia, que no puede recuperar el matrimonio roto unilateralmente, que se halla presionado por circunstancias de diversa índole (soledad, pobreza, enfermedad, etc.), ¿qué opción deberá tomar? Queda en pie la posibilidad de indagar si el matrimonio roto fue verdaderamente válido, si acaso no estará viciado por algún defecto que pueda dar lugar a una declaración de nulidad.

El caso del cónyuge inocentemente abandonado está pidiendo que se dé un paso adelante; hasta hoy para los divorciados vueltos a casar solo quedan como posibilidades estas: la reconciliación, una posible nulidad, guardar la continencia, la admisión a los sacramentos de la penitencia y de la eucaristía bajo ciertas condiciones... Pero siempre quedará el estigma de ser una persona divorciada. El cónyuge inocente no puede ser tratado a la par del divorciado culpable.

La teología y el derecho canónico deberán apurar la reflexión para dar respuestas más humanas a los conflictos en que se encuentran tantos hermanos. Privitera, inspirándose en la 'Economía' de la Iglesia Oriental, sugiere la posibilidad de hacer más flexible el principio de la indisolubilidad del matrimonio en vista a dar relieve al valor de la persona humana ${ }^{34}$. "El sábado es para el hombre, no el hombre para el 
sábado" (Mc. 2,27) es un principio evangélico que debería aplicarse sabiamente en esta situación.

En algunas iglesias locales se ha iniciado la experiencia del "catecumenado penitencial' para una atención pastoral a los divorciados vueltos a casar. Al cónyuge inocentemente abandonado parece que aún no se le hace la debida justicia. Este es un serio desafío a la reflexión y a la pastoral de la iglesia.

Una segunda consecuencia nace de la visión que se tiene al presente sobre el amor conyugal. La concepción del ex opere operato de la tradición eclesial ha influido demasiado, hasta el punto de hacernos pensar en una forma exageradamente positiva del cristiano, como si fuera impecable. El ex opere operantis cuenta en la teología renovada. Vaticano II dio relieve a las ciencias humanas como auxiliares para iluminar el pensamiento teológico: "a la luz del Evangelio y de la experiencia humana" (GS. n. 46) fue el criterio que asumió el Concilio para tratar los temas matrimoniales que le habían sido planteados.

El amor conyugal es una realidad humana, por tanto sometida al crecimiento y al desarrollo en vista a llegar a la perfección, pero también sometida a las vicisitudes del debilitamiento y de la muerte. La Iglesia Católica admite solo dos formas de cesación del vínculo conyugal (la muerte física del cónyuge y la declaración de nulidad), mientras que la Iglesia Oriental acepta otras formas de muerte del amor conyugal: la muerte psíquica (enfermedad mental), la muerte moral (cuando la convivencia de los cónyuges se hace moralmente imposible por diversas causas), la muerte civil (la condena a cadena perpetua) (35).

Algunos teólogos suelen hablar del 'venir a menos' del amor conyugal hasta poder concluir con la muerte irreversible del mismo (36). Se podría decir que los mismos signos que J. Bernhard señala para afirmar la 'no consumación existencial del matrimonio', valen para detectar que el amor conyugal 'ha venido a menos': brevedad de la vida en común, infidelidad desde el comienzo del matrimonio, ausencia de todo testimonio conyugal, dificultad para establecer una relación auténtica entre personas, intolerancia en la vida común, un matrimonio roto definitivamente (37).

J. M. Lahidalga ha hecho una propuesta que formula como dos casos distintos: el primero sería una declaración de nulidad del matrimonio ex tunc, es decir, una constatación de que no hubo desde el principio (desde la celebración de las nupcias) matrimonio alguno. Esta posibilidad ya ha sido contemplada en la Rota Romana y en otros tribunales eclesiásticos. El cardenal Vicenzo Fagiolo, siendo juez rotal, llevó adelante una causa de este tipo (38).

(34) Cfr. Salvatore Privitera, "Il principio dell'oikonomia nella Chiesa Orientale. Per un dialogo ecumenico in prospettiva etico-teologica", Ho Teologos 1 (1983) 153-182. Ver 174.

(35) Cfr. Bernhard HÄRING, Pastorale dei divorziati... Una strada senza uscita?, EDB, Bologna 1990, 48-53.

(36) Cfr. Giovanni CERETI, Matrimonio e indissolubilità. Nuove prospettive, EDB, Bologna 1971, 357-361.

(37) Cfr. Jean Bernhard, Divorcio e indisolubilidad del matrimonio, Herder, Barcelona 1973, 53.

(38) Cfr. Vincenzo Fagiolo, "Chicagien. Nullitatis matrimonii", Sacrae Romanae Rotae Decisiones seu Sententiae 62 (1970) 978-990; Santiago PANIZO ORALLO, "Las sentencias rotales del año 1970”, Revista Española de Derecho Canónico 37 (1981) 467-506; Pedro J. VILADRICH, “Amor y consentimiento. Sentencia rotal 'coram De Jorio' (19 Julio 1967). Amor conyugal y esencia del matrimonio", Jus Canonicum 12 (1972) 259-268. 
El segundo caso que analiza Lahidalga apunta a una posible nulidad del matrimonio ex nunc: se trataría de un matrimonio que en un comienzo fue válido, pero que con el correr del tiempo se deterioró y fracasó sin remedio. Esta segunda alternativa aún no ha entrado en los tribunales eclesiásticos (39). En algunos tribunales civiles de Europa, en el sistema alemán por ejemplo, se está abriendo la posibilidad de distinguir entre el divorcio-sanción (Verschuldensprinzip) y el divorcio-fracaso (Zerrütungsprinzip) (40).

Un teólogo norteamericano se ha permitido sugerir la elaboración de $A$ Theology for Failure - A Theology for Remarriage (una 'teología del fracaso', una teología para los divorciados vueltos a casar'), denunciando así el vacío existente en la Iglesia Católica de una reflexión sobre el fracaso (41), concretamente, el fracaso conyugal. Hasta hoy se ha conocido una actitud que él llama punitively, en vez de una postura de tipo redemptively (42) que sería de auspiciar. Esta actitud de 'divorcio-sanción' parece haber obedecido a un criterio en defensa de la 'institución' ('el favor juris') y no tanto de la 'persona'. El nuevo Código de Derecho Canónico se cierra con una proclamación de "la salus animarum (la salvación de los hombres) que debe ser siempre la ley suprema en la iglesia" (c. 1.752).

Una tercera consecuencia se deriva de la nueva concepción que se tiene de la sexualidad humana después del Concilio. La tradición eclesial relacionaba sexualidad con procreación. De ahí que se diera la prioridad ('fin primario del matrimonio') a la procreación. En esta misma perspectiva se concebían los derechos-deberes conyugales como el jus in corpus en orden a los actos de suyo aptos para la generación (c. 1081 §). Incluso el nuevo Código no ha logrado superar plenamente esta visión tradicional (c. $1061 \S 1)$.

La reflexión teológica, según la visión antropológica nueva, relee a la inversa la triple dimensión de la sexualidad: la concepción preconciliar subrayaba lo sexual como procreativo - placentero y finalmente relacional. Modernamente se debe leer así: relacional - placentero o gratificante - procreativo (43).

Con esta perspectiva se da un relieve especial a la dimensión relacional: la Biblia presenta a Yahvé creando al hombre como varón-mujer en orden a "hacerse una sola carne" (Gén 2, 24); las culturas del antiguo Oriente describían la realidad sexual con la imagen de 'chapa y llave' para expresar la vocación del encuentro interpersonal; la antropología moderna habla de la sexualidad como de 'lenguaje del amor' (44).

(39) Cfr. José María LAhidalga, "La declaración de nulidad y el matrimonio cristiano: una sugerencia pastoral", Surge 543-544 (1993) 45-63.

(40) (s.a) "Problemberichte zum Zeitgeschehen. Zum Reform des Ehescheidungsrechts", HerderKorrespondenz-Orbis Catholicus 24 (1970) 328-333.

(41) La revista Concilium ha dedicado dos números monográficos (n. 3 del año 1976 y n. 5 de 1990) al tema del 'fracaso del hombre'.

(42) Cfr. Georges R. Ewald, Jesus and Divorce. A biblical Guide for Ministry to divorced Persons, Herald Pres, Pennsylvania 1991, 120-125.

(43) Cfr. J. Silvio Botero G., Etica coniugale. Per un rinnovamento della morale matrimoniale, San Paolo, Milano 1994, 107.

(44) Cfr. Paul Eugène Charbonneau, Amor y libertad. Ensayo de moral conyugal, Herder Barcelona 1974, 146. 
De esta forma se da prioridad a la relación y la fecundidad no es más que consecuencia de una interrelación personal genuina. El Concilio parece hacer una nueva formulación del 'sentido del matrimonio': el 'bien de los cónyuges y el bien de los hijos', una primera fórmula, y la segunda 'el sentido unitivo y fecundo' (GS. nn. 48 y 51). M. Blondel supo en forma sintética relacionar estas dos dimensiones: "queriendo los dos ser una sola carne, se convirtieron en tres" (45).

Según la enseñanza conciliar, ¿qué pensar del cónyuge que es víctima de una negación unilateral, injusta, de modo permanente, de la relación marital que expresa y perfecciona el amor conyugal? Tradicionalmente la Iglesia le ha pedido una actitud heroica de continencia. No parece tan válida esta postura, máxime cuando no se ha preparado para el martirio a nuestros feligreses, ni ha sido llamado a la virginidad el cónyuge abandonado.

Se deben tener en cuenta varias circunstancias: la disposición al martirio no es tan frecuente en nuestro tiempo cuando la postmodernidad orienta hacia la 'ley del menor esfuerzo'; no se puede imponer, sin una debida motivación, la opción por la continencia; la enseñanza del Apóstol merece una consideración: "es mejor casarse que abrasarse" (I. Cor 7, 9); la conducta benigna y flexible de la Iglesia primitiva vuelve a ser un ejemplo de cómo actuar hoy en circunstancias muy similares; la tendencia pastoral inclina la balanza del lado de la misericordia.

La actitud de la Iglesia con los divorciados vueltos a casar, según las disposiciones pastorales de algunas iglesias locales, no puede ser la misma que se dispensa a quienes son responsables de una ruptura injusta y la que se da a quienes son víctimas inocentes. Se observa un silencio respecto a esta situación del cónyuge abandonado inocentemente, injustamente: ¿es un signo de impotencia disciplinar? ¿Es una señal de desinterés teológico por la búsqueda? ¿Es una manifestación de negligencia pastoral?

\section{CONCLUSIÓN}

"Vivir la verdad en el amor" (Efes. 4, 15) es el eslogan que Pablo formula para la construcción de la comunidad cristiana. Es muy significativo que los documentos del Concilio hayan recogido este lema repetidas veces. En alguna manera parece ser una traducción del criterio pastoral establecido por el mismo Vaticano II para afrontar los problemas del matrimonio y de la familia: "a la luz del Evangelio y de la experiencia humana". (GS. n. 46). El mismo magisterio pontificio de Juan Pablo II ha subrayado en diversas ocasiones la necesidad de integrar la doctrina y la vida concreta de la comunidad.

"Vivir la verdad en el amor" no solo es una inquietud del Papa o del Concilio. La historia de la salvación prácticamente ha sido escrita sobre esta clave: Yahvé hizo alianza con su pueblo elegido, fundando este pacto sobre el amor, un amor fiel y misericordioso. Israel cuando oraba a Yahvé, lo hacía recordándole a su Dios el

(45) Maurice Blondel, La acción. Ensayo de una crítica de la vida y de una ciencia de la práctica, BAC, Madrid 1996, 301. 
amor fiel y misericordioso que le había prometido (46). Aparece como una constante en la historia salvífica.

Se puede concluir diciendo que, por tanto, es un principio que debe estar a la base de la reflexión teológico-jurídica y de la acción pastoral de la Iglesia también hoy. De hecho, se observa un interés particular y un esfuerzo por conjugar los términos de la aporía 'doctrina y vida'. Es un intento de las tres grandes iglesias cristianas que está en sintonía con la revelación cristiana. Esa consonancia da una fuerza particular a la presión que viene de la base de la comunidad para que se haga justicia a ciertas situaciones en la Iglesia como es la del cónyuge abandonado injusta e inocentemente.

Juan Pablo II en la Familiaris consortio ha hecho una invitación especial en relación con 'las uniones libres de hecho', pero que puede aplicarse también al caso de los divorciados vueltos a casar y, por qué no, también a la situación del cónyuge abandonado inocentemente: "los pastores y la comunidad eclesial se preocuparán por conocer tales situaciones y sus causas concretas; caso por caso, se acercarán a los que conviven, con discreción y respeto; se empeñarán en una acción caritativa y de testimonio familiar cristiano que pueda allanarles el camino hacia la regularización de su situación" (n. 81).

La colaboración y participación de los laicos, de los casados, y aun de los divorciados, en la reflexión y en la acción pastoral, puede ser muy efectiva a la hora de buscar el encuentro entre 'ley y excepción', entre 'doctrina y vida', entre 'la verdad y el amor' (47).

La presente reflexión en nada pretende quitar fuerza al principio evangélico de la indisolubilidad matrimonial. Las palabras de un célebre Padre de la Iglesia primitiva, S. Juan Crisóstomo, definiendo la 'condescendencia divina', decía que es un "bajar para rehabilitar". Esto quiere decir que la condescendencia que hoy se espera de la Iglesia para con los hermanos en dificultad equivale a un comprender la situación de debilidad humana y del peso de las circunstancias históricas de quienes son víctimas de un abandono injusto dentro del matrimonio. Comprender la situación y hacer flexible la disciplina eclesial, al tiempo que se va habilitando a la 'persona en situación' para que pueda recuperarse e iniciar el camino hacia un mejor compromiso cristiano.

\section{RESUMEN}

La situación del 'cónyuge injustamente abandonado' es un problema que en el primer milenio, en el siglo XX y a comienzos del tercer milenio reclama atención especial. La conducta de la Iglesia en el primer milenio (Padres, Concilios, Penitenciales) da pie para establecer una 'analogía' con el momento presente en vista a la búsqueda de posibles soluciones. La sabia conjugación del binomio 'doctrina y vida concreta', 'verdad y amor', se está insinuando como un horizonte esperanzador en favor del cónyuge abandonado injustamente.

(46) Cfr. Gianfranco Ravasi, Il libro dei Salmi. Commento e attualizzazione I, II, III, EDB, Bologna 1985; Félix AsEnsio, Misericordia et Veritas. El 'Hesed' y 'Emet' divinos. Su influjo religiososocial en la historia de Israel, Aedes Universitatis Gregorianae, Romae 1949.

(47) Cfr. J. Silvio Botero G., "Teología del laicado. Nuevas perspectivas en el Postconcilio", Revista Teológica Limense 33/3 (1999) 327-350. 


\begin{abstract}
The situation of the partner in marriage, unjustly abandoned, is a problem which we find in the First Millennium, at the End of the XX Century and at the Beginning of the Third Millennium.

Regarding the attitude of the Church at the beginning of the christian era (Fathers, Councils, Popes) it is possible to establish an analogy between this attitude and theological reflection today in order to search for new solutions.

A wise reconciliation between doctrine and the concrete situation, between Truth and Love, suggests a perspective favorable to the partner unjustly abandoned. Also, a new concept of Love, Sexuality and Sacrament gives a new perspective to this problem.
\end{abstract}

